\title{
Pseudoathetosis as an Early Manifestation in a Patient with Multiple Sclerosis (Ms)
}

Isabelle Pastor Bandeira ${ }^{*}$, Washigton Luiz Gomes de Medeiros Junior', André Eduardo de Almeida Franzoi' Laura Fiuza Parolin², Paulo Roberto Wille ${ }^{3}$, Marcus Vinícius Magno Gonçalves ${ }^{4}$

'Department of Medicine, University of the Region of Joinville (UNIVILLE), Brazil

${ }^{2}$ University of the Region of Joinville (UNIVILLE), Brazil

University of the Region of Joinville (UNIVILLE), Brazil

${ }^{4}$ University of the Region of Joinville (UNIVILLE), Brazil

\section{Article Info}

\section{Article Notes}

Received: November 2, 2019

Accepted: February 7, 2020

\section{${ }^{\star}$ Correspondence:}

Dr. Isabelle Pastor Bandeira, Department of Medicine, University of the Region of Joinville. Rua Paulo Malschitzki, 10 - Zona Industrial Norte, CEP 89201-972, Joinville, Santa Catarina, Brazil; Telephone No: +55 419 9927-8674; E-mail: isabellepbandeira@gmail.com.

C 2020 Bandeira IP. This article is distributed under the terms of the Creative Commons Attribution 4.0 International License

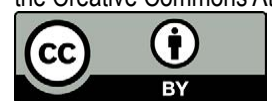

Keywords:

Multiple Sclerosis

Pseudoathetosis

Movement Disorders
Abstract

Pseudoathetosis is a movement disorder caused by loss of proprioception. The disorder is characterized by involuntary, slow, and writhing movements. Multiple sclerosis (MS) is an inflammatory demyelinating disease of the central nervous system (CNS). The disease is characterized by multiple lesions of the brain and spinal cord. These lesions are disseminated in time and space. The onset of the neuroinflammation is characterized by episodes of neurological dysfunction that usually recover. Reports of MS with pseudoathetosis are extremely rare. The association of these two disorders is uncommon. This article shows a 29-year-old woman who presented pseudoathetosis as the initial symptom of MS. Therefore, this case report is very relevant for medical knowledge due to the rare form presentation of MS.

\section{Manuscript}

Multiple sclerosis (MS) is a chronic inflammatory and demyelinating disease of autoimmune originate. The main agents responsible for the MS development include exogenous, environmental, and genetic factors. MS is characterized by multifocal and temporally scattered central nervous system (CNS) damage which lead to the axonal damage. Among clinical courses of MS it can be distinguish relapsing-remitting multiple sclerosis (RRMS), secondary progressive multiple sclerosis (SPSM), primary progressive multiple sclerosis (PPMS), progressiverelapsing multiple sclerosis (RPMS), clinically isolated syndrome (CIS), and radiologically isolated syndrome (RIS). Depending on the severity of signs and symptoms MS can be described as benign MS or malignant $\mathrm{MS}^{1}$.

MS diagnosis is based on McDonald's diagnostic criteria, which link clinical manifestation with characteristic lesions demonstrated by magnetic resonance imaging (MRI), cerebrospinal fluid (CSF) analysis, and visual evoked potentials. Among CSF laboratory tests used to the MS diagnosis are applied: Tibbling \& Link IgG index, reinbegrams, and CSF isoelectrofocusing for oligoclonal bands detection. It should be emphasized, that despite huge progress regarding MS as well as the availability of different diagnostics methods this disease is still a diagnostic challenge ${ }^{1}$.

The McDonald diagnostic criteria provide formal guidelines for the diagnosis of relapsing-remitting multiple sclerosis and primaryprogressive multiple sclerosis. These require demonstration of 

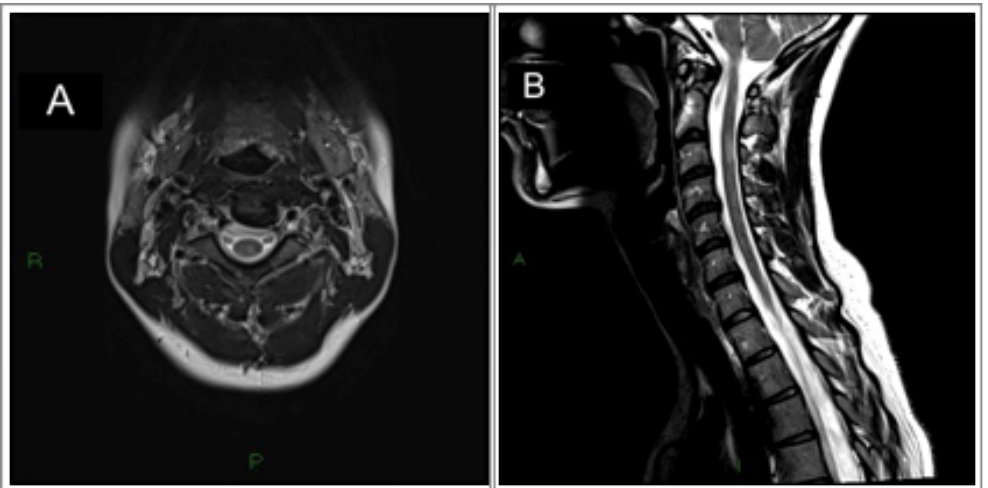

Figure 1: Axial T2-weighted (A) and Sagital T2-weighted images (B) show a small demyelinating lesion, slightly hyperintensity foci located on the right-side lateral medullar funicular, at the level of C3.

dissemination in space and time, with consideration given to both clinical findings and imaging data. The criteria also require that there exists no better explanation for the patient's presentation. The clinical history, examination, and MRI should be most consistent with MS, including the presence of features typical for the disease as well as the absence of features that suggest an alternative cause, for a diagnosis of MS to be proposed ${ }^{2}$.

Pseudoathetosis is a movement disorder that can be developed from lesions at all levels of proprioceptive sensory pathways. Hammond introduced this term in 1881, which comes from the Greek word athetosis meaning "without fixed position"3. In 1975 the term pseudoathetosis was introduced by Dooling and Adams to refer to movement disorder characterized by involuntary, slow and writhing movements. The disorder differs clinically from athetosis. The pseudoathetosis is manifested by loss of proprioception, whereas in athetosis there is no sensory loss ${ }^{4}$.

Various conditions that involve the posterior column have been reported to cause pseudoathetosis. These conditions include myelitis, spinal cord infarct, trauma, tumors, spondylotic myelopathy, leprosy, neuromyelitis optica spectrum disorder (NMOSD), and vitamin B12 deficiency ${ }^{5,6}$.The main lesion areas are the posterior column of the spinal cord, parietal cortex, thalamus, and peripheral nerves ${ }^{7,8}$.

Reports of MS with pseudoathetosis are extremely rare. We report a case that was diagnosed as MS but was associated with pseudoathetosis.

\section{Case Report}

A 29-year-old woman arrived at the emergency department complaining of sensory loss in her left arm. The patient had no medical history and did not use any medication. Neurological examination revealed left hemiataxia, pseudoathetosis in the upper left limb and Lhermitte's sign. At the moment, the course was pulse therapy with Solumedrol (Methylprednisolone 1000mg) for the next 5 days, prophylaxis for parasite infestations (single-dose of Ivermectin $6 \mathrm{mg}$ ) and gastric protection (Intravenous Omeoprazole $40 \mathrm{mg}$ ). Patient received orientations about the clinical hypothesis of demyelinating disease, as well as possible clinical complications of the disease (bladder dysfunction, motor, visual and sensory sequelae) and complications of the prescribed medications.

Laboratory tests revealed negative results for sexually transmitted diseases (HIV, VDRL and FTA-ABS). There was no vitamin B12 deficiency (count of $701 \mathrm{pg} / \mathrm{ml}$ - normal for adults is $300-900 \mathrm{pg} / \mathrm{ml}$ ). Liver and kidney functions were within normal limits. A lumbar puncture was performed and the examination of the cerebrospinal fluid (CSF) revealed normal cell count, normal CSF glucose, and normal CSF protein; CSF oligoclonal bands were positives. Imaging exams showed demyelinating lesions in the spinal cord [IMAGE], confirming the main diagnostic hypothesis of Multiple Sclerosis, as the pattern of spinal cord injury was not typical of NMOSD.

Based on clinical attack, CSF analysis and compatible lesions on magnetic resonance imaging, demonstrating the dissemination of lesions in space, the patient fulfilled McDonald's 2010 criteria for MS. She responded well to pulse corticosteroid therapy with remission of pseudoathetosis symptoms after 14 days. Thus, there was no symptomatic treatment for pseudoathetosis, and the patient was discharged with the diagnosis of active RRMS. Currently, she is under outpatient follow-up treatment of MS with immunomodulatory drugs.

\section{Discussion}

Multiple Sclerosis and other conditions that involve the posterior column have been reported to cause spinal pseudoathetosis ${ }^{9}$. Pseudoathetosis is also a very rare symptom in MS. Potulska-Chromik and colleagues reported a case of a 43-year-old woman with MS who presented transient involuntary movements of the right hand with coexisting loss of proprioception. Based on their research, 
they showed that this symptom is usually due to lesion of the proprioception pathway resulting in the dysfunction of the integration of the deep sensation with motor function with location in the striatum ${ }^{9}$.

Spitz et al described a 34-year-old MS patient who also presented pseudoathetosis as a movement disorder. She had sudden onset of involuntary movements in both hands and on her physical examination there was reduced deep sensation in both hands. In their study, they emphasized the importance of having an accurate evaluation of deep sensitivity whenever dealing with a patient with abnormal athetotic movements of extremities, since proprioception loss from different causes may lead to pseudoathetosis ${ }^{8}$.

In conclusion, pseudoathetosis may be considered a case of open-labeling for MS. This is rare, but we recommend that in the presence of pseudoathetosis ${ }^{9}$, should be considered the diagnostic hypothesis of MS, especially in young patients.

\section{Disclosures}

- Funding Sources and Conflict of Interest: No specific funding was received for this work and the authors declare that there are no conflicts of interest relevant to this work.

- Financial Disclosures for the previous 12 months: The authors declare that there are no additional disclosures to report.

- Ethical Compliance Statement: The authors confirm that the approval of an institutional review board was not required for this work. Even so, the patient signed a statement of consent (in Brazilian Portuguese - Termo de Consentimento Livre e Esclarecido) for the use of the information contained in the patient's medical record. We also confirm that we have read the Journal's position on issues involved in ethical publication and affirm that this work is consistent with those guidelines.

\section{References}

1. Kamińska J, Koper OM, Piechal K, et al. Multiple sclerosis - etiology and diagnostic potential. Postepy Hig Med Dosw Online. 2017 Jun 30; 71(0): 551-563.

2. Katz Sand I. Classification, diagnosis, and differential diagnosis of multiple sclerosis.Curr Opin Neurol. 2015 Jun; 28(3): 193-205.

3. Sharp FR, Rando TA, Greenberg SA, et al. Pseudochoreoathetosis: movement associated with loss of proprioception. Arch Neurol. 1994; 51: 1103-1109.

4. Dooling EC, Adams RD. The pathological anatomy of post hemiplegic athetosis. Brain 1975; 98: 29-45.

5. Seok HY, Jang SH, You S. Neuromyelitis Optica Spectrum Disorder Presenting with Pseudoathetosis. J Clin Neurol. 2018 Jan; 14(1): 123125.

6. Abboud H, Yu XX, Knusel K, et al. Movement disorders in early MS and related diseases: A prospective observational study. Neurol Clin Pract. 2019 Feb; 9(1): 24-31.

7. Lo YL, See S. Images in clinical medicine. Pseudoathetosis. N Engl J Med. 2010 Nov 4; 363(19): e29.

8. Spitz M, Aluízio Costa Machado A, et al. Pseudoathetosis Report of three patients. Movement Disorders. 2006; 21(9): 1520-1522.

9. Potulska-Chromik A, Rudzinska M, Nojszewska M, et al. Original article Clinical and neuroimaging correlation of movement disorders in multiple sclerosis: case series and review of the literature. Folia Neuropathologica. 2014; 1: 92-100. 


\section{Author Roles}

1. Isabelle Pastor Bandeira - research project: conception, design, organization and execution; manuscript preparation: writing of the first draft.

2. Washigton Luiz Gomes de Medeiros Junior - research project: conception, design, organization and execution.

3. André Eduardo de Almeida Franzoi - research project: conception, design, organization and execution.

4. Laura Fiuza Parolin, MD - Manuscript Review and Critique

5. Paulo Roberto Wille, MD, PhD - Manuscript Review and Critique

6. Marcus Vinícius Magno Gonçalves, MD, PhD - Manuscript Review and Critique 